\title{
The Research of Problems and Countermeasures in the Connection Between Secondary and Higher Vocational Education
}

\author{
Jianyu Wang \\ Guangzhou panyu polytechnic, Guangzhou, 511483, China \\ email: wangjy@gzpyp.edu.cn
}

Keywords: higher vocational education, connection between secondary and higher vocational education, countermeasures

\begin{abstract}
The system of the connection between secondary and higher vocational education is not perfect is an important internal factors affecting the healthy development of Higher Vocational Education. It is mainly reflected in the professional course content repetition, cultural basic course disjointed, skills training courses "upside down" etc. Therefore, should take the classification training and flexible teaching, modular course system, reform methods of examination and enrollment.
\end{abstract}

\section{Introduction}

With the rapid development of China's social economy and economic globalization, the economic structure of industry of our country is changing, talent structure and content requirements is changed yet. The enterprise demand for high-skilled talents is growing. Therefore, vigorously develop vocational education, cultivating a large number of talents with high skills, not only is the development of occupation education in our country under the new situation, but also the social development necessity for talent structural.

In the past ten years, the higher vocational education in our country has obtained the rapid development, has occupied half of the country in the whole higher education system. But behind the rapid development of higher vocational education, the quality and quantity of the students has potential crisis. Some vocational school students lack, quantity and quality declined. Investigate its reason, besides external factors of the birth rate and the population decreased and college enrollment, the internal factors of connection between secondary and higher vocational education system is not perfect should be the main factors.

\section{The main mode of the connection between secondary and higher vocational education}

The connection between secondary and higher vocational education in China started in the eighty's of last century, after 20 years of exploration and practice, has formed a connection between secondary and higher vocational education mode of their. From the point of view of higher vocational education, the mode of connection in our country mainly has the following several.

Counterpart enrollment mode

The model is students completed three years vocational learning in secondary school, technical school, vocational school enter in the professional counterparts higher vocational colleges learning two to three years, through the entrance examination of higher vocational education by individual organizations. At present, vocational students generally take $3+X$ examination. " 3 " refers to the Chinese, mathematics, English three basic courses. which generally unified proposition, examination and grading by the administrative departments of education in higher vocational college's province. " $X$ " refers to the comprehensive professional examinations, determined by the higher vocational colleges, and according to the requirements of training and recruitment characteristics, proposition, examination and grading.

Five year consistent system model

This is model of our earlier trial in the connection between secondary and higher vocational 
education. The implementation five year consistent system higher vocational colleges recruit fresh graduates of junior middle school, five years of schooling, the entrance examination is as the same as ordinary secondary school. Generally is divided into two stages of organizing teaching. The first stage is the public class teaching, mainly to learn basic knowledge of culture, general ability training. The second stage is learning the professional basic courses and specialized courses, learning theory and occupation ability.

\section{$3+2 / 3+3$ or $4+2$ mode.}

The model is that the higher vocational colleges and secondary vocational schools hook, implemented through joint education. To recruit the junior high school graduates first study for 3 years or 4 years in secondary vocational schools, then according to certain the proportion or formed class, through the higher vocational colleges test, to higher vocational colleges study for 2 years or 3 years.

The counterpart enrollment and five year consistent system is two main modes of the connection between secondary and higher vocational education personnel training in the present stage. The advantage of five years consistent pattern is unity based, small age, strong plasticity. System consistently, it is easy to optimize the teaching process. Five years of schooling, effective teaching time is long, is beneficial for both theoretical teaching and practical ability training, to enable students to systematically master professional knowledge, and can form good occupation morals and stable professional thinking. But this model is influenced by resources and students, development scale and speed is limited.

Counterpart enrollment mode, recruit professional vocational graduates, it can not only make full use of the abundant education resources, and is conducive to the realization of the goal of higher vocational education, developed a practical, skilled talents of high quality. But because of secondary and higher vocational implementation training plan respectively, the difference of the students quality structure is very obvious, to carry out substantive connection has certain difficulty, and cohesion have different levels gap of knowledge and skills or repeated problems.

\section{The main problems and reasons of connection between secondary and higher vocational education}

After years of exploration and practice, research on the connection between secondary and higher vocational education in China has achieved certain progress, also summed up many effective cohesion in practical work. At present, China's higher vocational colleges generally use the counterpart enrollment mode. In the connection between secondary and higher vocational education many problems is still exist, especially in the courses connection, the problem is prominent, which is mainly manifested in the following aspects.

Repeat the course content

At present, around the country, the unified curriculum standards are not formulated, unified teaching materials of connection secondary and higher vocational through are lack yet, especially the professional course teaching materials. Because of vocational schools and vocational colleges determine their own course system and teaching content, result in some professional curriculum content repetition. For Guangzhou Panyu Polytechnic 2010, 2011 Applied Electronic Technology Major as an example, there are a lot of repetition in professional basic courses and specialized courses in secondary and higher vocational education, some courses not only as the name, course system and contents are basically the same. For example: circuit analysis, principle and application of single chip computer courses, students have learned in the secondary stage, and in higher vocational education stage, these classes are continued to be offered, not only result in waste of higher vocational education resource and learning time, but also seriously affect the students learning interest and enthusiasm.

\section{Cultural basic course incoherence}

After students come in vocational colleges, learning of the cultural basic course is generally more difficult, especially in mathematics, physics and English language courses. Investigate its reason, it mainly is the existence of philosophy of "skills rather than cultural, emphasizing operation 
and light theory" in vocational school. This reflects differences in ideology and principle of curriculum structure design of secondary and higher vocational.

Skill training course "upside down"

During the internship training and professional skills training, higher vocational and secondary vocational school should reflect the differences in the level of content, but the actual situation is not so. Regardless of the device, the teachers, training methods and training management, in many higher vocational colleges there are obvious problems, some even less than the secondary vocational school, which resulting in higher vocational skills training courses "upside down" phenomenon.

The core and key connection between secondary and higher vocational education is the connection of curriculum. From the view of higher vocational education, the main causes of the problem is that some higher vocational colleges in our country has not solved very common and outstanding problem of the students quality is not balanced, in determining the direction of personnel training and the teaching goal, did not take into account the quality differences of different sources, so then resulting in many problems in secondary and higher vocational cohesion.

According to the current policy, vocational college students mainly come from two aspects: The first is the ordinary high school graduates; second are graduates from secondary vocational school, while the main source is the former. Because of personnel training goal of the common senior high school and vocational school is different, so there are great differences in the curriculum plan, make the foundation quality of the students in higher vocational colleges uneven. The students enrolled by vocational college in senior middle school and vocational school are obviously not in the same starting line, of course, these students together in class is very difficult. Therefore, cultivating mode of these two types of students have different personnel training mode. However, at present, many higher vocational colleges use the same training way on two types of students. In determining the direction of personnel training and the teaching goal, ignore the two different source quality differences. No special settings a set of the talent training mode and training objectives for vocational students, But to curriculum and teaching according to the ordinary high school students for students training model and the teaching goal. So, in the connection between secondary and higher vocational education, there are inevitably the lack of the knowledge and skills or redundancy problem. Not only the secondary vocational school students cannot use the knowledge learned, waste of resources in vocational education, but also increased the difficulty of running school in higher vocational colleges, make it hard to achieve the aim of higher vocational education.

\section{Countermeasures and suggestions on cohesion}

The implementation of classification training and flexible teaching, both the culture of different qualities of the students

Higher vocational education in foreign countries has many successful experiences in solving the uneven quality of students. According to the "international education standard UNESCO launched in 1997 March classification" (ISCED), before entering the higher vocational college study, two different types of students are required to transition course tuition corresponding. German college as an example, its student source is composed of two parts: One is the "dual system" training occupation education graduates, before entering the college must obtain the junior high school diploma, so it generally must first to cram 1 - 2 years. The other is liberal arts school (complete high school system, 13 years of general education and culture) graduates. Before entering college, this class of graduates must go to the relevant enterprises to obtain occupation practice experience, usually for about half a year.

From the present situation of occupation teaching in our country, at this stage, to carry out the transition education to promote vocational cohesion is very difficult. Therefore, in order to effectively solve the problems of higher vocational curriculum in our country, higher vocational colleges should develop different talents mode and professional teaching plan for two different types of students, And through separate classes, the implementation of classification training and separate teaching. 
At present, the credit system as the core of the flexible learning system practiced in the colleges is conducive to the consideration of different student quality cultivation. After the implementation of credit system, according to the knowledge and ability structure characteristics of different students, reflect the corresponding differences in the requirements of culture courses, professional courses and skills courses. And let the students choose the right, allowing different backgrounds of the students flexible elective courses and learning content according to their own development and the provisions of the credit system. For example, secondary vocational school students can be excused from courses learned in secondary vocational school, and take some basic courses to improve their knowledge structure.

To break the discipline teaching mode, establish modular course system

The biggest defect of the traditional occupation education is not to get rid of the discipline system in our country. Cultural courses, technical basic course, specialized courses and practice teaching are arranged by stages. All kinds of curriculum own their system. This inevitably leads to higher vocational courses repetition in contents in the same profession. Therefore, the connection education between secondary and higher vocational must break in subject teaching mode, take "wide base, flexible module" for the principle, to the post, occupation ability as the core, In order to meet the needs of local economic and social development, according to the occupation post (group) content of the work and the national occupation (industry) standards as well as occupation evaluation, plan as a whole content and teaching system in secondary and higher vocational education, determine the required knowledge structure, ability structure and technique structure, construct adjust and improve unified modular curriculum system composed by the culture course module, professional course module, professional elective courses, elective course module, training course module. according to the different training objectives of secondary vocational and higher vocational education and different types of students' knowledge and ability structure, selects some modules as curriculum combined to determine the curriculum design, teaching content and teaching materials in the secondary vocational and higher vocational curriculum.

Constructing modular curriculum system based on the position, occupation ability as the core, to realize the integration of theoretical teaching and practical teaching, which can not only overcome the curriculum content duplication, reduce the number of courses, improve courses cohesion quality, but also highlight the characteristics of the occupation teaching, be conducive to employment and the future development of students.

Reform the enrollment mode, the implementation of "wide into severe out" system

Enrollment examination in higher vocational colleges for vocational students, directly relates to the connection between secondary and higher vocational education in the course. Therefore, based on careful study of secondary vocational and higher vocational curriculum plan, higher vocational colleges must clearly put forward the uniform examination standard for admission of higher vocational education.

According to the characteristics of occupation education and foreign experience, in higher vocational education entrance stage, must emphasize the admission requirements on theory and practice is equally important. Therefore, in the higher vocational enrollment examination, the professional skills assessment and culture courses test are equally important. Culture examination content should be based on the syllabus of secondary vocational school. The culture test difficulty and the total score ratio should not be too high, in order to adapt to the higher vocational learning principle.

In order to avoid vocational education into the "examination-oriented education" misunderstanding, a variety of forms should be taken. For example, we can learn from foreign experience, the implementation of "wide into severe out" system. Allows fresh students and non fresh vocational graduates apply for higher vocational education. Fundamentally break through the limitation of secondary vocational students to enter oneself for an examination in higher vocational colleges. At the same time, forming a new concept of focus on pay attention to education from the connection between turned to focus on the cohesion of the connotation.

Research and practice of the connection between secondary and higher vocational education is 
the foundation work of accelerating the reform and development of higher vocational education, at the same time it is a system engineering involving a wide range, complicated content. Although the great achievements in the research practice on the connection have be made, but due to historical and practical reasons, there are still many problems need to be researched and solved. Therefore, the relevant government departments should increase the intensity of participation in vocational education, strengthen macro management, straighten out the various links, and give full play to the role of occupation colleges. Based on the research and Practice on the relevant problems, standardize professional and curriculum construction, formulate specific unified course standard, to further improve the connection system between secondary and higher vocational education, promote the healthy development of China's occupation education.

\section{References}

[1] Y.F. Liu On the Connection of Secondary and Higher Vocational Education Mode [J]. Occupation Technology Education: English edition version. , 2002，23（10）: 5-7.

[2] Y. Gao The Research of Connection of Secondary and Higher Vocational Education [J]. The Higher Occupation Education. 2004 (5) : 43-45.

[3] Y. Gao, Y. Cao, Yonghua Luo Analysis of Present Situation and Countermeasures of the Connection Between Secondary and Higher Vocational Education in Our Country [J]. Vocational Education Forum, 2004 (24): 11-13.

[4] J. Wu,Y. Shi The Existing Problems in the Connection Between Secondary and Higher Vocational Education from the View of Higher Vocational Education and the Countermeasures [J]. Journal of Zhejiang Ocean University.2008(12):117-120

[5] Q.K. Li The Reseaech on the Link Between Secondary Vocational Schools and Higher Vocational Colleges [J]. Journal of Tianjin Vocational Institutes.2011(3):3-11 